\title{
The Use of Digital Evidence in Human Trafficking Investigations
}

\author{
Isabella Chen and Celeste Tortosa
}

Please cite this article as: I Chen and C Tortosa, 'The Use of Digital Evidence in Human Trafficking Investigations', Anti-Trafficking Review, issue 14, 2020, pp. 122-124, https://doi.org/10.14197/atr.201220149

In 2018, a woman from Venezuela claimed asylum in Austria on the grounds of being a victim of human trafficking. Her claim led to an extensive criminal investigation and seventeen women pressed charges against six defendants. The non-governmental organisation LEFÖ-Intervention Centre for Trafficked Women and Girls (LEFÖ-IBF) — provided psychosocial and legal assistance to the women. This case was exceptional both in terms of the volume of digital evidence gathered and the testimonies of the women. The investigation ultimately led to the convictions of the perpetrators and the awarding of EUR 280,000 (approx. USD 310,000) as compensation to the victims.

As LEFÖ-IBF staff who supported the women, we observed first-hand how technology in general and evidence gathered from digital technologies in particular can open up new possibilities in criminal proceedings. However, we also witnessed the negative impact of the use of digital evidence on the women. This calls for a critical assessment of the use of digital evidence in human trafficking investigations and its consequences for trafficked persons.

The women in this case migrated from Venezuela to Austria and were subsequently sexually exploited in private apartments and hotels. Instagram had played a substantial role in their recruitment. The strategy of the traffickers was to attract the attention of young Venezuelans by displaying a luxurious life in Europe. They also advertised high-paying jobs either in the sex-industry as 'VIP Escort Services' or as hostesses in restaurants. Instagram photos were curated to great aspirational effect and presented the illusion of a lush European lifestyle, which, in turn, established a foundation of trust between the women and the traffickers. Once the women accepted the job offer, communication switched to WhatsApp, e-mail and direct messages on Facebook and Instagram. The women had to send a picture of their passports via WhatsApp and eventually nude photos too. The traffickers then sent them their plane tickets to Austria.

Once in Austria, the traffickers took pictures to advertise the women on local sexual service websites, and the ads included a short description of the services 
offered. In an attempt to mitigate concerns about revealing their actual identity, the women were told that these websites were not accessible in Venezuela and their families would never see the websites and pictures.

The traffickers managed the clients by phone and informed the women accordingly. The profit arrangement between the women and the traffickers was a 50-50 share of the income. Since the women had to bear the costs for rent, online advertisement and work necessities, in reality, they received around 20 per cent of the money the clients paid. The women had no freedom to refuse clients or sexual practices and the sexual exploitation was aggravated by constant humiliation and degradation. When they informed the traffickers about sexualised violence and humiliation from clients, the traffickers laughed it off.

The traffickers messaged the women constantly and they had to be available round the clock. In addition, traffickers exerted control through threats that they would publish the pictures on Instagram, or tell the women's families via Facebook that they were working as prostitutes, or physically harm them. Due to their lack of proficiency in the German language and accumulated debts, as well as the pressure to send money to their families in Venezuela, the women found themselves in a state of dependence.

Immediately upon receiving the first testimony in 2018, the Austrian police started following the phone calls from the traffickers, tracking the apartments where they exploited the women and mapping the scope and dimension of the criminal group. They recorded over 50,000 telephone calls, WhatsApp messages and Facebook private messages. From the traffickers' Facebook profiles, as well as from the sexual services websites, the police were able to draw conclusive evidence of human trafficking and sexual exploitation. In the process, they identified more trafficked women. Eventually, twenty women received assistance from LEFÖ-IBF, according to their individual needs. Services offered ranged from assisting with secure accommodation to psychosocial and legal assistance. Seventeen of them participated in trial and gave testimonies.

With the help of digital evidence, law enforcement was able to trace the working hours, working conditions, threats and logistics of transport, as well as the daily income and the constant control and abuse of the women. Despite the amount of data gathered, the digital evidence-social media messages and posts, and audio recordings - were only used to strengthen the women's testimonies but not replace them. In Austria, the system of criminal proceedings still relies heavily on the victim's testimony.

This case was exceptional in the sense that digital evidence was used in order to support the credibility of the exploited women. Too often, however, we have seen cases based entirely on women's testimonies. On one hand, we welcome the fact that digital evidence was gathered and incorporated into the case and it validated 
the women's stories. However, the burden remained on them to 'prove' their exploitation, and thus their 'victimhood'. In their case, the digital evidence was consistent with what they conveyed to law enforcement. But what about victims who have experienced exploitation but whose digital traces appear to law enforcement as inconsistent?

Using digital technologies and social media to recruit people into forced labour situations and to exploit them through heightened surveillance and control opens the door for novel legal strategies to prosecute traffickers. Indeed, as evidenced by this case, the digital traces gathered by law enforcement proved indispensable in building the case against the perpetrators. At the same time, we are convinced that anti-trafficking stakeholders' obsession with the role of technology in human trafficking does not live up to its hype.

Addressing human trafficking as a technological challenge presents a limited understanding of exploitation and does not offer a holistic approach to the protection of trafficked persons. Instead of focussing on how technology can be used in criminal prosecutions, we need to determine how technology can enable trafficked persons to exercise their rights. A myopic focus on technology to address exploitation draws attention away from the role of labour markets and restrictive migration policies in creating the conditions that allow traffickers to exploit their victims - through technology or otherwise. The anti-trafficking community must continuously keep trafficked persons at the centre of any intervention.

Isabella Chen is a Project Manager at LEFÖ-IBF working in the areas of research, policy, and advocacy. She coordinates two projects—one on safe and voluntary return of trafficked persons and another on strengthening the right to residence and protection for third-country nationals trafficked to Europe. She has a BA in Social Anthropology from the University of Vienna. Her research interests include the European Union's migration policy and its links to human trafficking, gender, and racism. Email: chen.isabella@icloud.com

Celeste Tortosa is a psychosocial and legal counsellor at LEFÖ-IBF, where she works primarily with women from Latin America and Nigeria. Her research interests include compensation and the right to residence permits for trafficked persons. She holds two MAs in Sociology and Social Work from the University of Buenos Aires. Previously, she has worked as a researcher in the field of fundamental rights and torture at the Observatorio del Sistema Penal y los Derechos Humanos at the University of Barcelona. Email: celetortosa@gmail. com 